\title{
ГАЛЕКТИН-3 КАК НОВЫЙ БИОМАРКЕР ПРИ ХРОНИЧЕСКОЙ СЕРДЕЧНОЙ НЕДОСТАТОЧНОСТИ
}

\section{GALECTIN-3 AS A NEW BIOMARKER IN CHRONIC HEART FAILURE}

\author{
A. Zinkina \\ Yu. Trusov \\ K. Bogdanov \\ E. Moskalev
}

Summary. Heart failure is considered an epidemic disease, affecting $1 \%$ to $2 \%$ of the world's adult population. At the moment, an urgent problem is the study of new biological markers of chronic heart failure, which would become effective tools for monitoring the quality of applied personalized medicine, early diagnosis, accurate prediction of clinical outcome, which together is of great importance for stratification of patient risk. This paper presents the results of the performed analysis of studies devoted to the use of galectin-3 as a biomarker of heart failure. The analyzed studies can be divided into 4 categories: studying the value of a substance for diagnosis; studying risk stratification for the most effective and adequate therapy; controlling the body's response to the prescribed and implemented therapy; predicting morbidity and mortality both in the short term and in the long term.

Keywords: heart failure, galectin-3, biomarker, NT-proBNP, predictive value, diagnostic value. ердечная недостаточность считается эпидемическим заболеванием, которым страдает от 1\% до 2\% мирового взрослого населения [1]. Сердечная недостаточность представляет собой многофакторное системное заболевание, при котором после повреждения сердца активируются структурные, нейрогуморальные, клеточные и молекулярные механизмы, которые действуют как сеть для поддержания
Зинкина Анна Алексеевна

Аспирант, ФГБОУ ВО «Самарский государственный медицинский университет» Министерства здравоохранения Российской Федерачии anna-zinkina@mail.ru

трусов Юрий Александрович Аспирант, ФГБОУ ВО «Самарский государственный медицинский университет» Министерства здравоохранения Российской Федерачии

Богданов Кирилл Михайлович Врач клинической лабораторной диагностики, ГБУЗ «Самарская областная клиническая больница имени

В.Д. Середавина»

Москалев Еуджиниу

Аспирант, ФГБОУ ВО «Самарский государственный медицинский университет» Министерства здравоохранения Российской Федерачии

Аннотация. Сердечная недостаточность считается эпидемическим заболеванием, которым страдает от $1 \%$ до 2\% мирового взрослого населения. На данный момент актуальной проблемой является исследование новых биологических маркеров хронической сердечной недостаточности, которые стали бы эффективными инструментами мониторинга качества применяемой персонализированной медицины, ранней диагностики, точного прогноза клинического исхода, что в совокупности имеет огромное значение для стратификации риска пациента. В данной работе приводятся результаты выполненного анализа исследований, посвященных использованию галектина-3 в качестве биомаркера сердечной недостаточности. Проанализированные исследования можно разделить на 4 категории: изучающие ценность вещества для диагностики; изучающие стратификацию риска для максимально эффективной и адекватной терапии; контролирующие ответ организма на назначенную и реализуемую терапию; прогнозирующие заболеваемость и смертность как на короткий период, так и на долгосрочную перспективу.

Ключевые слова: сердечная недостаточность, галектин-3, биомаркер, NTproBNP, прогностическая ценность, диагностическая ценность.

физиологического функционирования. Эти скоординированные, сложные процессы приводят к повышенной симпатической активности, перераспределению кровообращения, что является причиной развития различных, параллельно развивающихся клинических признаков и симптомов. Эти признаки и симптомы сводятся к неспецифической клинической картине, что диктует необходимость использования инвазивных 
и неинвазивных диагностических инструментов для постановки точного диагноза и определения основной причины заболевания [2].

Наиболее важным фактором, определяющим исход сердечной недостаточности, является ее постоянное прогрессирование. Постоянная оптимизация фармакотерапевтических режимов, новые цели и тонкая регуляция этих процессов пытаются удерживать эти компенсаторные механизмы в физиологическом диапазоне. Помимо фармакологической терапии, варианты интервенционной и хирургической терапии открывают новые возможности в лечении сердечной недостаточности. Известно, что чем раньше выявлена патология, тем результативнее лечение [3]. Таким образом, на данный момент актуальной проблемой является исследование новых биологических маркеров хронической сердечной недостаточности, которые стали бы эффективными инструментами мониторинга качества применяемой персонализированной медицины, ранней диагностики, точного прогноза клинического исхода, что в совокупности имеет огромное значение для стратификации риска пациента.

Сегодня активно используется только один биомаркер хронической сердечной недостаточности (XCH) - мозговой натрийуретический пептид (BNP) [4]. Определение уровня BNP и N-концевого фрагмента его предшественника (NT-proBNP) применяется в ходе скрининга нарушения функций желудочков сердца, для постановки диагноза и дальнейшего прогноза результативности реализуемой терапии ХСН. Уровень данных показателей напрямую зависит от индивидуальных особенностей пациента: пола, возраста, массы тела, наличия мерцательной аритмии и почечной недостаточности [5]. Это еще раз подчеркивает необходимость поиска новых современных биомаркеров ХCH.

- Галктин-3 (имеет также другие обозначения: L29, Мас-26 (ВР-35) является ßотвечает за активацию Т-клеток, нейтрофилов и лаброцитов;

- отвечает за запуск ангиогенеза и апоптоза;

- отвечает за регулирование клеточной адгезии;

- способен индуцировать и ингибировать клеточный рост с дальнейшей дифференциацией.

Помимо этого, вещество увеличивает силу противовоспалительных сигналов, так как характеризуется хемотаксическим действием доя моноцитов и макрофагов., а также принимает участие в фагоцитозе макрофагами нейтрофилов. Галектин-3 почти не выявляется в кардиомиоцитах, в то время как миокардные фибробласты экспрессируют высокую долю рассматриваемого вещества [7].

Проведенные исследования продемонстрировали экспрессию галектина-3 мРНК у лабораторных крыс, которые имели артериальную гипертензию. Позднее было выявлено, что вещество в высоком содержании присутствует у животных с сердечной недостаточностью на стадии прогрессирования $[8,9]$.

Современные исследования также продемонстрировали зависимость от дозы нарастания экспрессии галектина-3 в сосудистых клетках гладких мышц лабораторных животных в ответ на альдостерон, нарастание протекает в течение 24 часов после введения. Гиперэкспрессия рассматриваемого протеина в 1.6 раза выше депозиции коллагена I типа. [10].

Проведенный литературный обзор литературных источников показал высокий потенциал галектина-3 в качестве биомаркера. Проанализированные исследования можно разделить на 4 категории:

1. Изучающие ценность вещества для диагностики.

2. Изучающие стратификацию риска для максимально эффективной и адекватной терапии.

3. Контролирующие ответ организма на назначенную и реализуемую терапию.

4. Прогнозирующие заболеваемость и смертность как на короткий период, так и на долгосрочную перспективу.

\section{Ценность вешества $\triangle \wedge$ Аиагностики}

Исследование 2006 года показало, что между тяжестью пациент и уровнем галектина-3 нет корреляции. При этом было выявлено, что галектин-3 уступает NTproBNP в плане диагностической специфичности [11].

На основании результатов другого исследования можно сделать вывод о том, что у пациентов с сердечной недостаточностью с сохранной и сниженной фракцией выброса, чему соответствует повышенный уровень галектина-3 в сыворотке крови, отмечается более выраженный фиброз миокарда, это ведет к прогрессированию диастолической дисфункции. Из данного исследования вытекает, что определение галектина-3 имеет высокое диагностической значение, при этом определение галектина-3 в совокупности с NT-proBNP позволяет определить тип сердечной недостаточности, оценить результат терапии, уточнить степень тяжести, разработать прогноз и оценить риски отрицательного исхода [12].

\section{Стратификачия риска}

Исследование, проведенное объединением авторов «CORONA Study Group» выявило, что у пациентов, у которых уровень галектина-3 в плазме крови был ниже или равен среднему значению, частоты первичных конечных точек в ходе терапии розувастатином 
снижалась на $30.6 \%$ относительно пациентов, которые получали плацебо ( $p=0.019)$. Целью этого исследования было определение эффективности терапии розувастатином у пациентов с сердечной недостаточностью систолического типа ишемического происхождения с низким уровнем галектина-3. В исследовании приняли участие 1492 пациента, у 411 из них в течение 33 месяцев были зарегистрированы случаи инфаркта миокарда, нефатального инсульта, смерти в результате сердечно-сосудистых причин [13]. Также в ходе данного исследования было обнаружена следующая корреляция: у пациентов, у которых уровень галектина-3 в плазме крови выше среднего уровня, терапия с применением розувастатина является более эффективной.

Другое исследование, которое было проведено Valsartan Heart Failure Trial, было выявлено, что у пациентов, у которых уровень галектина-3 в плазме крови ниже среднего уровня, при терапии с применением валсартана, снижалась частота госпитализаций по поводу хронической сердечной недостаточности. При этом для пациентов, у которых уровень содержания галектина-3 в плазме крови выше среднего уровня, терапия с применениям валсартана была неэффективна $[14,15]$.

Рассмотренные исследования имеют особое значение для оценки и понимания роли галектина-3 в качестве биомаркера сердечно-сосудистых заболеваний, однако до сих пор данный протеин не используется в клинической практике. Это обуславливает необходимость реализации дополнительных экспериментов и исследований для оценки влияния фармакотерапии на уровень галектина-3 в плазме крови, оценки ценности вещества относительно стратификации рисков и разработки прогнозов клинических исходов заболевай сердечно-сосудистой системы.

\section{Контро^ь И наблюАение за эффективностью терапии}

Нельзя недооценивать важность влияния реализуемой фармакотерапии на уровень галектина-3 в плазме крови в качестве биомаркера сердечной недостаточности и других заболеваний сердечно-сосудистой системы. На данный момент имеющиеся исследования концентрируют внимание на определении исходного уровня данного протеина.

К примеру, было выполнено исследование, в ходе которого выполнялись замеры галектина-3 в плазме крови у пациентов с терминальной стадией хронической сердечной недостаточности до и после имплантации левого желудочка, искусственного сердца или операции по трансплантации сердца (всего в иссле- довании участвовали 55 человек). Полученные показатели сравнивались с людей, не страдающих сердечно-сосудистыми заболеваниями (средний уровень рассматриваемого протеина в плазме крови составил 4.08 нг/мл). Было выявлено существенное повышение уровня галектина-3 в плазме крови у пациентов, страдающих ХНС (в среднем, уровень составил 11.2 нг/мл), в то время как замена левого желудочка и механическая разгрузка сердца не влияли на снижение уровня галектина-3 в плазме крови [16].

Другое исследование продемонстрировало повышение уровня галектина-3 в плазме крови у пациентов, которые умерли в результате полиорганной недостаточности, относительно пациентов, которые выжили и затем перенесли трансплантацию сердца. В исследовании приняли участие 151 человек, у которых кровообращение поддерживалось искусственным путем [17].

Другое исследование было реализовано Cardiac Resynchronizationin Heart Failure с целью изучения, насколько плазменная концентрация галектина-3 зависит от сердечной ресинхронизирующей терапии. Длительность исследования составила 18 месяцев, в нем приняли участие 270 пациентов с хронической сердечной недостаточностью. Было обнаружено, что уровень NTproBNP демонстрирует положительный эффект реализуемой терапии, а плазменная концентрация галектина-3 меняется несущественно на фоне положительных изменений состояния пациентов, принимающих ресинхронизирующую терапию [18].

Имеющиеся исследования говорят о том, что на данный момент нет точных сведений и данных, которые могли би подтвердить ценность галектина-3 в кровяной плазме или сыворотке в качестве биомаркера для контроля эффективности применяемой терапии.

\section{Прогностическая ро^ь}

Исследование, организованное PRIDE, было посвящено изучению, насколько галектин-3 ценен для прогностической ценности в течение коротких периодов. В исследовании были задействованы 209 человек. Было выявлено, что при сердечной недостаточности большей диагностической ценностью обладает NT-ptoBNP, в данном плане он превышает галектин-3, а вот более результативным предиктором краткосрочной смертности является галектин-3 [13].

Другое исследование, реализованное CARE-HF, продемонстрировало, что начальная плазменная концентрация галектина-3 коррелирует с показателями госпитализации и смертности пациентов с хронической сердечной недостаточностью. В частности, при плаз- 
менной концентрации галектина-3 свыше 30 нг/мл в 2 раза увеличивался риск наступления госпитализации и смертности от ХНЛ [18].

Исследование, реализованное HF-ACTION показало, что риск наступления госпитализации и смертности от ХНЛ увеличивался в последовательности: высокий галектин-3/ низкий NT-ptoBNP, низкий галектин-3/ высокий NT-ptoBNP, высокий галектин-3/высокий низкий NT-ptoBNP [19].

Прогностическая ценность рассматриваемого протеина также была изучена в исследовании DEAL-HF, в котором приняли участие 233 пациента с XCH. Исследование длилось 6.5 лет. Было выявлено, что у 50\% пациентов плазменная концентрация галектина-3 превышала норму, при этом она была в корреляции с уровнем NT-ptoBNP и возрастом пациента. Прямой выраженной зависимости между индикатором фракций выброса, генеза сердечной недостаточности и плазменной концентрацией галектина-3 выявлено не было. Было выявлено, что галектин-3 является мощным предиктором смертности из-за $\mathrm{CH}$ и ХСН. Исследование позднее было проведено с увеличением длительности наблю-

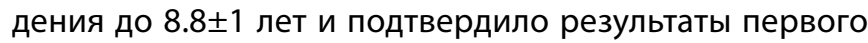
исследования [20].

Важно учитывать, что уровень галектина-3 ассоциировался с почечной дисфункцией, которая часто является спутником XCH.

\section{ОбсужАение и выво ы}

Выполненный анализ исследований подтвердил возможность и высокий потенциал применения галектина-3 в качество биомаркера сердечной недостаточности. Однако для реализации возможности его эффективного использования в клинической практике и в ходе разработки современных лекарственных средств, необходимы дополнительные исследования.

\section{ЛИТЕРАТУРА}

1. Tanai E, Frantz S. Pathophysiology of Heart Failure. Compr Physiol. 2015 Dec 15;6(1):187-214.

2. Mosterd A, Hoes AW. Clinical epidemiology of heart failure. Heart. 2007 Sep;93(9):1137-46.

3. Gedela M, Khan M, Jonsson 0. Heart Failure. S D Med. 2015 Sep;68(9):403-5, 407-9.

4. Максимов М.Л. Влияние кардиоселективного бета-блокатора небиволола на глобальную и локальную сократимость миокарда у больных ишемической болезнью сердца, осложненной хронической сердечной недостаточностью. Автореф. дис. .. канд. мед. наук. М., 2004.

5. Драпкина 0.М., Дуболазова Ю.В. Применение биологических маркеров в диагностике диастолической сердечной недостаточности. Журн. Сердечная недостаточность. 2011; 12 (6).

6. Kim H, Lee J et al. Expression and immunohistochemical localiza- tion of galectin-3 in various mouse tissues. Cell Biol Int $2007 ; 31$ (7): 655-2.

7. Sharma UC et al. Galectin-3 marks activated macrophages in fai- lure-prone hypertrophied hearts and contributes to cardiac dysfunc- tion. Circulation 2004; 110 (19): 3121-8.

8. Shroen B, Heymans $S$ et al. Thrombospondin-2 is essential for myocardial matrix integrity: increased expression identifies failure- prone cardiac hypertrophy. Circ Res 2004; 95 (5): 515-22.

9. Calvier L et al. Galectin-3 mediates aldosterone-induced vascular fibrosis. Atheroscler Thromb Vasc Biol 2013; 33 (1): 67-75.

10. Felker GM et al. Galectin-3 in ambulatory patients with heart failure: results from the HF-ACTION study. Circ Heart Fail 2012; 5 (1): $72-8$.

11. Kjekhus J et al. CORONA group. Rosuvastatin in older patients with systolic heart failure. N Engl J Med 2007; 357 (22): 2248-61.

12. Дуболазова Ю.В. Оценка клинического течения хронической сердечной недостаточности с сохраненной фракцией выброса. Автореф. дис канд. мед. наук. М., 2012.

13. Gullestad L, Ueland T, Kjekshus J, Nymo SH, Hulthe J, Muntendam P, Adourian A, Böhm M, van Veldhuisen DJ, Komajda M, Cleland JG, Wikstrand J, McMurray $\mathrm{JJ}$, Aukrust P; CORONA Study Group. Galectin-3 predicts response to statin therapy in the Controlled Rosuvastatin Multinational Trial in Heart Failure (CORONA). Eur Heart J. 2012 Sep;33(18):2290-6.

14. Cohn JN et al. Valsartan Heart Failure Trial Investigators. A rando- mized trial of the angiotensin-receptor blocker valsartan in chronic heart failure. N Eng J Med 2001; 345 (23): 1667-75.

15. Anand IS, Rector TS, Kuskowski M, Adourian A, Muntendam P, Cohn JH. Baseline and serial measurements of galectin-3 in patients with heart failure: relationship to prognosis and effect of treatment with valsartan in the Val-HeFT. Eur J Heart Fail. 2013 May;15(5):511-8.

16. Milting $\mathrm{H}$ et al. Plasma biomarkers of myocardial fibrosis and re- modeling in terminal heart failure patients supported by mechanical circulatory support devices. J Heart Lung Transplant 2008; 27 (6): 589-96.

17. G. Erkilet, S. Schulte-Eistrup, M. Morshuis, B. Bohms, D. Roefe, J. Gummert, H. Milting. Plasma galectin-3 is increased in terminal heart failure patients and is elevated in patients surviving mechanical cir- culatory support. J Heart Lung Transplant 2010; 29 (2): S65.

18. Lopez-Andrès N, Rossignol P, Iraqi W, Fay R, Nuée J, Ghio S, Cleland JGF, Zannad F, Lacolley P. Association of galectin-3 and fibrosis mar- kers with long-term cardiovascular outcomes in patients with heart failure, left ventricular dysfunction and dyssynchrony: insights from CARE-HF (Cardiac Resynchronization in Heart Failure) trial. Eur J Heart Fail 2012 Jan;14(1):74-81. 
19. Felker GM, Fiuzat M, Shaw LK, Clare R, Whellan DJ, Bettari L, Shirolkar SC, Donahue M, Kitzman DW, Zannad F, Piña IL, O'Connor CM. Galectin-3 in ambulatory patients with heart failure: results from the HF-ACTION study. Circ Heart Fail 2012; 5 (1): $72-8$.

20. Lok D, Der Meer PD, Bruggink-André de la Porte PW, Lipsic E, Wijngaarden JV, Hillege HL, van Veldhuisen DJ I. Prognostic value of galectin-3, a novel marker of fib- rosis, in patients with chronic heart failure: data from DEAL-HF study. Clin Res Cardiol 2010; 99 (5): 323-28.

(c) Зинкина Анна Алексеевна ( anna-zinkina@mail.ru ), Трусов Юрий Александрович,

Богданов Кирилл Михайлович, Москалев Еуджиниу.

Журнал «Современная наука: актуальные проблемы теории и практики»

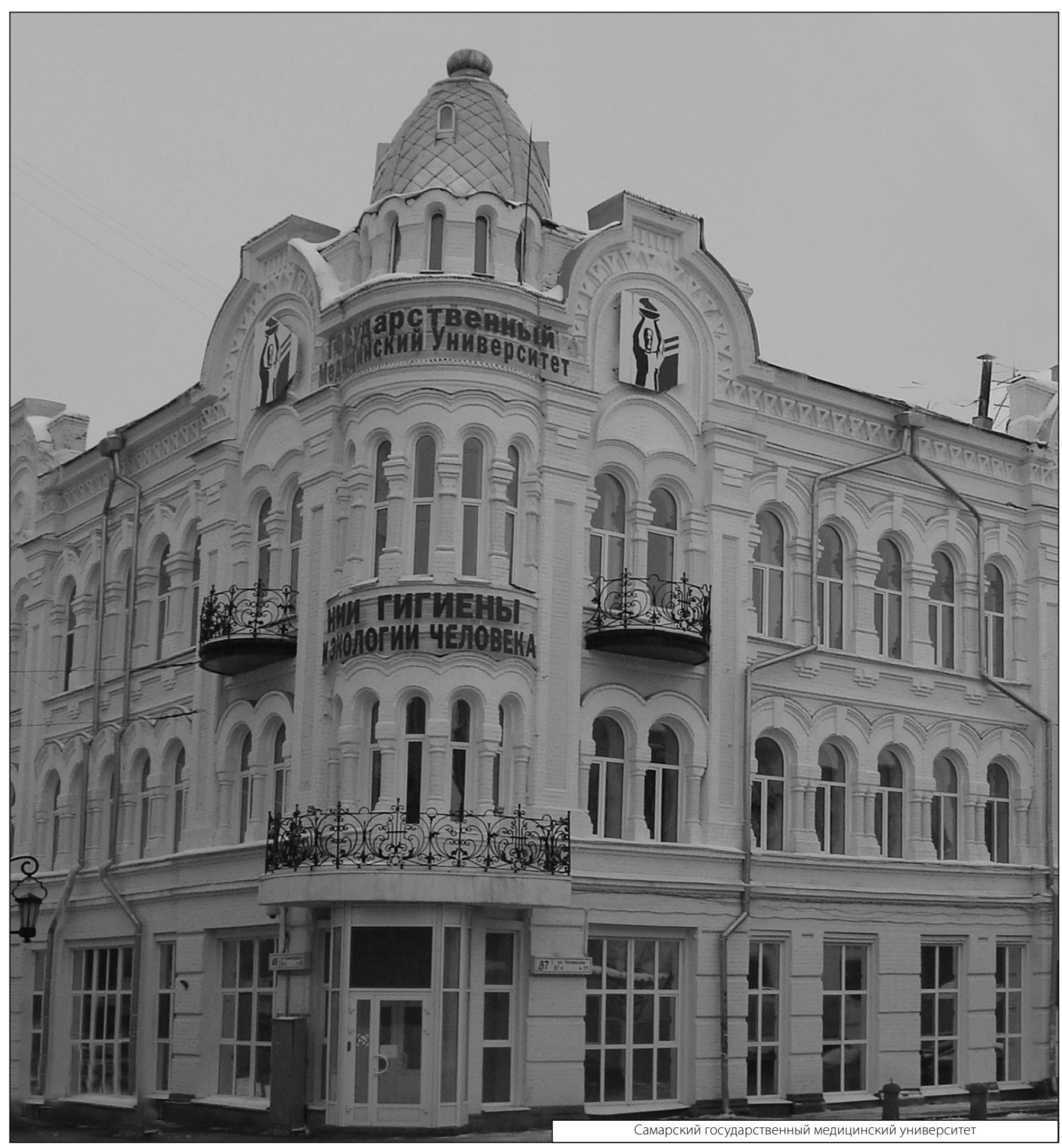

